\title{
Análise comparativa entre métodos de carregamento de cargas e análise postural de auxiliares de enfermagem
}

\author{
Eduardo Concepción Batiz ${ }^{\text {a* }}$, Lizandra Garcia Lupi Vergara ${ }^{\mathrm{b}}$, \\ Olga Elena Anzardo Licea ${ }^{\mathrm{c}}$ \\ a*eduardo.batiz@sociesc.com.br, 1ST, Brasil \\ blizandra@deps.ufsc.br, UFSC, Brasil \\ 'oanzardo@yahoo.com.br, Joinville, Brasil
}

\begin{abstract}
Resumo
Os auxiliares de enfermagem estão expostos a cargas de trabalho prejudiciais à saúde devido a vários fatores, dentre eles o peso a ser manipulado, as posturas assumidas e as condições físicas do ambiente hospitalar. 0 objetivo deste artigo é apresentar os resultados da aplicação de três métodos, dois relacionados com carregamento de carga e outro de análise postural, a fim de verificar a existência de riscos de problemas dorsolombares em auxiliares de enfermagem na manipulação e carregamento de pacientes. Para atingir o objetivo do trabalho, foi aplicado o Método N1OSH, o “Guia Técnico para Avaliação e Prevenção dos Riscos Relativos à Manipulação Manual de Cargas” e o método REBA. Os resultados mostraram a existência de sintomas de fatiga e dores no corpo, principalmente na região lombar, dorsal e cervical dos auxiliares de enfermagem e que o peso manipulado está acima do valor recomendado pelos dois métodos aplicados, caracterizando alto risco dorsolombar.
\end{abstract}

Palavras-chave

Carregamento de cargas. Auxiliares de enfermagem. Análise postural.

\section{Introdução}

Durante toda a vida, o ser humano se expõe constantemente a riscos que, se não são tomadas medidas adequadas de controle, podem levar à ocorrência de fatos que provoquem acidentes ou alterações no estado de saúde. Esses riscos estão relacionados com o trabalho, como também em atividades cotidianas, e muitas vezes são determinados por fatores de risco de origem física, química, biológica e psicofisiológica.

0 auxiliar de enfermagem é um exemplo de profissional que está frequentemente exposto a diversos riscos de saúde, dados às características próprias do trabalho que vão desde a relação com pacientes até a manipulação direta e indireta de fluidos corpóreos e sangue.

Segundo a Classificação Brasileira de Ocupações (CBO), os auxiliares de enfermagem devem prestar assistência ao paciente zelando pelo seu conforto e bem estar, administrar medicamentos e desempenhar tarefas de instrumentação cirúrgica, posicionando de forma adequada o paciente e o instrumental, organizar ambiente de trabalho e dar continuidade aos plantões (BRASIL, 2002).

Os transtornos musculoesqueléticos (TME) se constituem no problema mais comum entre os relacionados com o trabalho na União Europeia. A manipulação manual de cargas, o trabalho em posturas prolongadas e/ou forçadas e os movimentos repetitivos representam fatores de risco de TME (MAGAZINE, 2007).

0 manuseio de cargas - em especial o levantamento de cargas - deve ser considerado como trabalho pesado. Mesmo que o consumo de energia e a frequência do pulso não aumentem significativamente, a carga nas 
costas é frequentemente tão elevada que podem surgir complicações patológicas futuras. 0 problema principal do manuseio de cargas não é tanto a exigência dos músculos, mas sim o desgaste dos discos intervertebrais (KROEMER; GRANDJEAN, 2005).

A manipulação de pacientes, e mais especificamente o carregamento deles pela equipe de auxiliares de enfermagem para o traslado a diferentes atividades, como realização de exames, mudança de posturas por necessidades médicas ou dos próprios pacientes, o banho, etc., representa por si só uma atividade de risco ergonômico. Entre os fatores de risco que podem estar presentes nesta atividade e que influenciam diretamente na manipulação, levantamento, mobilização e transporte de pacientes, estão:

- Peso dos pacientes;

- Espaço físico inadequado à realização dos procedimentos durante a manipulação;

- Falta de capacitação do pessoal;

- Tempo de exposição à tarefa;

- Complexidade da "carga" a ser manipulada;

- Falta de equipamento mecânico que permita minimizar os esforços.

Estas situações podem ser agravadas quando as patologias impossibilitam a ajuda do próprio paciente, o que aliviaria a atividade de carregamento pelos auxiliares de enfermagem. Estes fatores são responsáveis por diversos casos de lesões nas costas e no sistema musculoesquelético dos auxiliares de enfermagem. $\mathrm{Na}$ atualidade, as dores e as lesões nas costas de que sofrem os trabalhadores em qualquer tipo de atividade industrial, têm-se convertido em um tema de preocupação internacional (CENTRO..., 2010).

Os danos aos discos intervertebrais com suas consequências na coluna e nas pernas representam problemas tanto pessoal como econômico. Estas doenças na coluna provocam dores e limitam fortemente a mobilidade e a vitalidade das pessoas. Elas conduzem a uma ausência prolongada do trabalho e configuram hoje como uma das principais causas de invalidez prematura. Elas são relativamente frequentes no grupo etário dos 20 a 40 anos. Certas profissões, especialmente expostas a este problema, por exemplo, pessoal de cuidados especiais, mostram mais frequentemente doenças dos discos intervertebrais (KROEMER; GRANDJEAN, 2005).

Os problemas musculoesqueléticos são identificados como o principal fator de risco nos trabalhadores de estabelecimentos de serviço de saúde já que estão expostos a posturas de trabalho estressantes, manipulação de cargas pesadas e percursos grandes, que podem chegar até a 18 $\mathrm{km}$ diários (REMESAL, 2010). Associa-se em muitas ocasiões a sobrecarga física e problemas musculoesqueléticos (ENGELS, LANDEWEERD, KANT, 1994 apud GÓMEZ-MORAN; VIVAS, 2001), provavelmente causados pela adoção de posturas de trabalho inadequadas, o carregamento de pacientes e o deslocamento de grandes pesos (OWEN, 1985; SCHOLEY, 1983; SUTBBS et al., 1983; WRIGHT, 1981 apud GÓMEZ-MORAN; VIVAS, 2001).

Pode-se citar como exemplo da gravidade do problema, em um ano, cerca de 8.780 trabalhadores da área de saúde, de um total de 370.000 em Ontário, Canadá, sofreram lesões laborais com perdas de jornadas de trabalho e indenizações a cargo do Ontario Safety Association for Community and Healthcare - OSACH (OSACH, 2006 apud MAGAZINE, 2007). Destaca-se ainda que mais de um terço $(42,0 \%)$ das lesões foram motivadas pela manipulação de pacientes e mais da metade foram por lesões musculoesqueléticas. Estima-se que os custos diretos da compensação de lesões de trabalhadores na atenção sanitária em Ontário elevam-se a 34 milhões de dólares canadenses por ano.

0 presente artigo tem como objetivo apresentar os resultados de aplicação de três métodos, sendo dois de avaliação de carregamento de cargas e outro de análise postural, na identificação de riscos ergonômicos a que os auxiliares de enfermagem estão submetidos em atividade de trabalho, especificamente na manipulação e carregamento de pacientes do leito hospitalar até a cadeira de rodas e vice-versa.

\section{Justificativa}

Alguns dos TME mais comuns relacionados ao trabalho são a lombalgia, a dor no pescoço, as tendinites do braço e ombro e a síndrome do túnel do carpo. Destaca-se que, em 2005, um a cada quatro trabalhadores europeus se queixavam de dores nas costas, estimando um custo total para a economia e a sociedade entre 0,5 e $2 \%$ do produto interno bruto (MAGAZINE, 2007).

Grande parte dos traumas musculares entre os trabalhadores são causados pelo manuseio de cargas, sendo aproximadamente $60 \%$ dos problemas musculares por levantamento de cargas e $20 \%$ por puxá-las ou empurrá-las (BRIDGER, 2003 apud IIDA, 2005).

Os limites aos movimentos de diferentes partes do corpo têm sido pesquisados amplamente em muitos países, podendo-se encontrar informações correspondentes a outras populações (VAN COT; KINKADE, 1972; SANDERS; McCORMICK, 1993). Estudos realizados em diversos países demonstram como a atividade de enfermagem está entre as de 
maiores riscos com relação a dores e lesões nas costas. 0 professor A. Magora (CENTRO..., 2002), em um estudo realizado em lsrael em 1970, analisa e classifica oito distintas profissões como as de maior risco de dores e lesões nas costas dos trabalhadores, sendo que o segundo lugar, imediatamente depois da indústria pesada, é a de enfermagem. Ressalta ainda que Delhin e seus colaboradores em 1976 mencionam que 46,8\% de 267 enfermeiras de um hospital geriátrico da Suécia apresentavam dores nas costas. lgualmente Stubbs, em 1983, com uma amostra de 3912 enfermeiras do Serviço Nacional de Saúde da Grã-Bretanha, demonstra que 43,1\% têm sofrido dores nas costas, sendo que 17\% destas causaram baixa laboral, com uma perda global de 750.000 dias de trabalho em um ano. Um estudo realizado na Califórnia em um hospital de 600 leitos revelou que, em um período de seis meses, 52\% das pessoas entrevistadas tinham sofrido dores nas costas em consequência de seu trabalho (HARBER, 1985 apud CENTRO..., 2002).

As atividades de manipulação de pacientes merecem a atenção de especialistas na proposição de medidas para eliminar ou pelo menos reduzir os efeitos que tal exposição pode estar provocando nesses profissionais.

Um dos fatores que condiciona a aparição de sobrecarga e fadiga física é a manipulação e transporte de cargas, especialmente do pessoal de enfermagem que realiza mobilização e traslado de enfermos (média de 25 levantamentos ou mudanças posturais por jornada de trabalho) (MERCHÁN; JURADO, 2007).

A manipulação e traslado de pacientes são uma das causas frequentes de acidentes nos hospitais. As lesões ocorrem no sistema musculoesquelético e se apresentam, principalmente, nas costas e nos membros superiores devido a riscos presentes na carga (pacientes) e às condições de manipulação (VALENZUELA, 2004). A mesma autora destaca que entre os fatores que determinam a alta incidência de lesões estão as posturas associadas à manipulação, os esforços realizados durante o traslado, o design de equipamentos hospitalares que não levam em conta os princípios da Ergonomia.

Nesse sentido, o tema do artigo se encaixa dentro da área de Engenharia do Trabalho uma vez que trata de riscos de saúde ocupacional, avaliada a partir da comparação entre dois métodos de carregamento de cargas (N1OSH e Guia Técnico para Avaliação e Prevenção dos Riscos Relativos à Manipulação Manual de Cargas, este último do Instituto Nacional de Seguridad e Higiene del Trabajo de Espanha) e de um método de análise postural (REBA) que se adapta exatamente às características das atividades desenvolvidas pelos auxiliares de enfermagem, objeto de estudo deste artigo.

0 tema discutido contribui de forma significativa na identificação da existência representativa ou não de riscos à saúde dos auxiliares de enfermagem na atividade de carregamento de cargas, e ainda auxilia na compreensão do método espanhol, não muito conhecido, mas de grande valor para a Ergonomia, Segurança e Saúde do Trabalho, além da área de Gestão de Riscos de Acidentes do Trabalho.

\section{Procedimento metodológico}

Trata-se de um estudo de caso aplicado em dois hospitais onde foram utilizados métodos quantitativos, a partir de ferramentas de avaliação ergonômica; e qualitativos, através de técnicas específicas como questionários, além da análise comparativa entre os métodos aplicados para a situação analisada - atividade de manipulação de pacientes. Conforme procedimento metodológico proposto, o estudo foi dividido em cinco etapas descritas abaixo.

Em uma primeira etapa, após realizar um período de ambientação, aplicando a técnica de observação direta, foi elaborado e aplicado um questionário com o objetivo de conhecer as características da população analisada, desde o ponto de vista demográfico até as possíveis dores apresentadas e as partes do corpo mais afetadas, assim como outros fatores de interesse para a pesquisa.

Em uma segunda etapa, foram efetuadas fotografias e filmagens das atividades realizadas pelos auxiliares de enfermagem no carregamento de pacientes, para identificar tanto a atividade específica para aplicação dos métodos propostos, quanto para determinar as diferentes posturas e segmentos do corpo envolvidos na atividade para aplicação do método de análise postural.

Em uma terceira etapa foram aplicados o Método NIOSH e o Método espanhol “Guia Técnico para Avaliação e Prevenção dos Riscos Relativos à Manipulação Manual de Cargas”, com o propósito de fazer uma comparação entre os resultados quando analisada a atividade de carregamento de pacientes do leito até a cadeira de rodas e vice-versa e, sobretudo comprovar se o método espanhol, menos conhecido que o método NIOSH, é factível de ser aplicado na atividade analisada. Ambos os métodos são apresentados no item 3.2.

Na quarta etapa, foi aplicado o método REBA (Rapid Entire Body Assessment) para análise das posturas adotadas pelos auxiliares de enfermagem e para conhecer os possíveis riscos de danos à saúde, e finalmente na quinta etapa, foram diagnosticados 
os problemas ergonômicos e propostas soluções para melhoria das condições de trabalho destes profissionais da área da saúde.

\subsection{Seleção da amostra}

Para o desenvolvimento da presente pesquisa, foi selecionada uma amostra de 35 auxiliares de cinco unidades de internação de dois hospitais diferentes com atividades semelhantes, o correspondente a 92,1\% do total de trabalhadores destas unidades estudadas, amostra representativa da população total de auxiliares de enfermagem. A população atende a 123 leitos de unidades de internação feminina com pacientes de várias especialidades.

Entre as diferentes atividades que os auxiliares de enfermagem realizam e que estão relacionadas com o carregamento de pacientes, foi selecionada especificamente a transferência de pacientes entre o leito e a cadeira de rodas e vice-versa, pelas condições inadequadas em que são realizadas.

A população de auxiliares de enfermagem é predominantemente feminina, como pode ser observado na Figura 1. Em um total de 35 auxiliares que compõem a amostra, $28(80 \%)$ são do sexo feminino e apenas $7(20 \%)$ do masculino. As idades estão concentradas fundamentalmente entre as faixas etárias de 26 e 40 anos, representando $77,1 \%$ do total, sendo que 12 destes (34,3\% do total da amostra) estão entre 36-40 anos.

Os problemas musculares decorrentes do manuseio de cargas são originados por vários fatores, principalmente devido à grande variação individual das capacidades físicas, treinamentos insuficientes e frequentes substituições de trabalhadores homens por mulheres (IIDA, 2005). Sendo a amostra analisada fundamentalmente feminina, a probabilidade de riscos de problemas musculares decorrentes do manuseio de cargas - pacientes -, é muito maior nestes auxiliares de enfermagem.

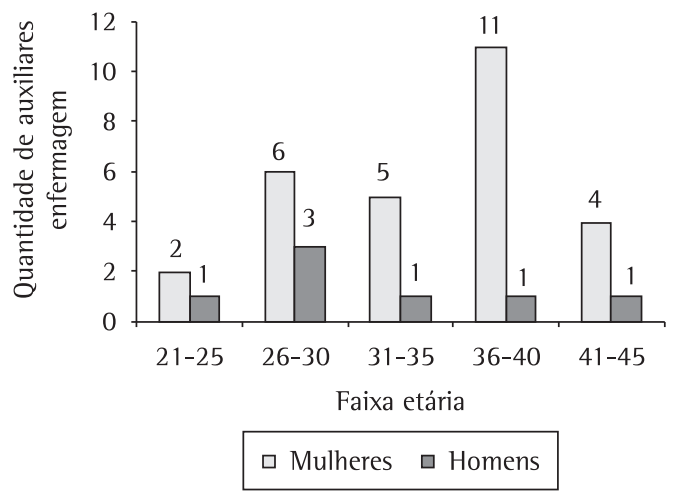

Figura 1. Representação da faixa etária e sexo dos auxiliares de enfermagem.

\subsection{Métodos aplicados}

A seguir são descritos de forma sucinta os três métodos que foram aplicados na atividade analisada.

\subsubsection{Método NIOSH para avaliação do carregamento de cargas manuais}

Através da aplicação do método N1OSH é possível verificar se o posto de trabalho oferece risco à coluna vertebral do trabalhador e definir qual seria a carga ideal para a situação em estudo e, ainda, estabelecer modificações visando melhorias nestes postos de trabalho.

0 método descreve que há uma carga limite ideal de $23 \mathrm{~kg}$ para se erguer adequadamente, sem oferecer sobrecarga à coluna vertebral do trabalhador. Mas, como cada situação de trabalho é única, com características próprias, nem sempre é possível encontrar nestes locais as características ideais definidas pelo NIOSH para o limite de $23 \mathrm{~kg}$. Precisa-se, então, definir para cada situação de trabalho, em que o levantamento de carga é tarefa principal, a carga limite recomendada, e para isso é necessário considerar aspectos como: as características da carga, de sua embalagem, seu peso real, a posição desta carga no espaço, a distância de alcance, o tempo e frequência de manutenção da carga (BATIZ, 2001).

0 método N1OSH se fundamenta em dois índices:

- Carga limite recomendado (CLR);

- Índice de levantamento (IL).

A equação de cálculo do CLR é a seguinte:

$$
C L R(k g)=23 \times f H \times f V \times f D \times f F \times f A \times f l
$$

onde:

- 23: peso limite ideal a ser erguido sem risco particular quando a carga está idealmente colocada, a frequência de levantamento é menor que uma vez a cada 5 minutos e a apreensão da carga é fácil e confortável.

- FH: fator corretivo para a posição horizontal da carga tanto na origem quanto no destino do levantamento. 0 valor de $\mathrm{FH}$ é de 1 para $\mathrm{H}=25 \mathrm{~cm}$;

- FV: fator corretivo para a altura vertical da carga tanto na origem quanto no destino da tarefa. 0 valor FV é de 1 para $\mathrm{V}=75 \mathrm{~cm}$ (altura do punho);

- FD: fator corretivo para a distância vertical percorrida, definido como a distância de deslocamento vertical do objeto. 0 valor 1 é uma distância $\leq 25 \mathrm{~cm}$;

- FA: fator corretivo para assimetria de movimento (levantamento com rotação do tronco);

- FF: fator corretivo para a frequência de levantamento. Este fator só será 1 se a frequência de levantamento for $\leq 0,2$ e o tempo de duração da atividade $\leq 1$. Para as restantes combinações, este fator influi de forma negativa no cálculo da carga limite recomendada; 
- Fl: fator corretivo levando em conta a interface mão-carga.

A equação de cálculo do ll é a seguinte:

$I L=\frac{\text { Peso real da carga }}{C R L}$

onde:

- Il $<1$ : a chance de lesão é mínima;

- $1<\mathrm{ll}<2$ : aumenta o risco;

- IL > 2: aumenta bastante o risco de lesões da coluna e do sistema musculoligamentar.

\subsubsection{Método espanhol: guia técnico para avaliação e prevenção dos riscos relativos à manipulação manual de cargas}

0 objetivo de aplicação deste método foi verificar a possibilidade de ser utilizado como uma ferramenta em uma atividade tão específica como é o carregamento de pacientes, que difere do carregamento de cargas nas empresas, constituindo-se em uma prática inovadora (ESPANHA, 2010a). Não existem antecedentes no Brasil da aplicação deste método para a atividade de carregamento de pacientes até o momento de realização da pesquisa.

0 método espanhol aplicado estabelece, para cada caso específico, os valores máximos de cargas toleráveis para a manipulação manual em condições adequadas à segurança e saúde dos trabalhadores, através da análise de fatores, tais como: características individuais, frequência de manipulação da carga, distância vertical que percorre a carga, ângulos de giros e o peso teórico recomendado em função da zona de manipulação, sendo que o maior peso teórico recomendado é de $25 \mathrm{~kg}$, o que possibilita conhecer quais os fatores que interferem mais negativamente, quais poderiam ser modificados e quais seriam as medidas preventivas e corretivas mais eficazes a serem implantadas.

0 peso aceitável é um limite de referência teórico, de forma que, se o peso real das cargas transportadas é maior que este peso aceitável, muito provavelmente se constituirá em uma situação de risco. É importante ressaltar que os valores dos diferentes fatores de correção se encontram entre 0 e 1 e que o peso teórico máximo que pode ser carregado em condições ideais é de $25 \mathrm{~kg}$.

A expressão geral que o método fornece para o cálculo do peso aceitável para a manipulação da carga é:

Peso Aceitável $=$ Peso teórico $\times$ Fator correção espaçamento vertical $\times$ Fator correção giro $\times$

Fator correção agarre $\times$ Fator correção frequência

onde:
- Peso aceitável: é o limite de referência teórico, considerando a influência de todos os fatores que compõem a expressão;

- Peso teórico: recomendado em função da zona de manipulação. 0 valor máximo recomendado é $25 \mathrm{~kg}$ quando a carga é manipulada na altura do cotovelo e separada a uma distância de até $25 \mathrm{~cm}$ do corpo. Na medida em que a carga é manipulada mais longe do corpo e em alturas inferiores ou superiores a altura do cotovelo, menor será a carga que deve ser manipulada;

- Fator de correção do espaçamento vertical: é a distância que percorre a carga desde que se inicia o levantamento até finalizar a manipulação. A distância adequada corresponde a um valor menor ou igual a $25 \mathrm{~cm}$;

- Fator de correção do giro do tronco: o giro pode ser estimado pelo ângulo que formam as linhas que unem a parte posterior dos pés com a linha dos ombros. No caso específico deste método, o fator de correção só terá valor 1,0 quando não existirem giros do tronco;

- Fator de correção do tipo de pega: a classificação em três estágios para a pega das cargas: bom $(1,0)$, regular $(0,95)$ e ruim $(0,9)$;

- Fator de correção da frequência de manipulação: quantidade de carregamentos realizados em um intervalo de tempo. Nota-se que o fator de correção só terá valor 1,0 quando for realizado um carregamento a cada 5 minutos e a atividade não durar mais que uma hora. Se o tempo entre um carregamento e outro diminuir e/ou a duração da atividade for maior que uma hora, o valor do fator de correção será sempre menor que 1,0 .

A Consolidação das Leis Trabalhistas - CLT no Art. 198 da CLT estabelece:

É de $60 \mathrm{~kg}$ (sessenta quilogramas) o peso máximo que um empregado pode remover individualmente, ressalvadas as disposições especiais relativas ao trabalho do menor e da mulher. (BRASIL, 1943).

No ano de 2005 o Senado Federal do Brasil emitiu o Parecer $n^{\circ} 1.337$ sobre o Projeto de Lei do Senado $n^{\circ} 19$, de 2003, que propõe a alteração do art. 198 da Consolidação das Leis do Trabalho. Dessa forma ficaria da seguinte maneira: "Art. 198. É de $30 \mathrm{~kg}$ (trinta quilogramas) o peso máximo que um empregado pode remover, individualmente, ressalvadas as disposições especiais relativas ao trabalho do menor e da mulher. (NR)" (BRASIL, 2005).

Ambos os métodos sugerem que o peso a ser carregado seja muito abaixo do recomendado pela CLT.

Por outra parte, a NR-17 no item 17.2.2 estabelece que 
[...] não deverá ser exigido nem admitido o transporte manual de cargas, por um trabalhador cujo peso seja suscetível de comprometer sua saúde ou sua segurança. (BRASIL, 1978).

0 método espanhol considera que a manipulação de carga cujo peso seja maior de $3 \mathrm{~kg}$ pode provocar risco dorsolombar não tolerável. Como ambos os métodos acima descritos sugerem valores de carregamento de cargas manuais em condições ideais entre 23 e $25 \mathrm{~kg}$, o presente artigo se baseia nestes índices para a determinação do peso máximo que deveria ser carregado por um trabalhador, garantindo sua saúde e segurança laboral.

\subsubsection{Método REBA}

0 Método REBA (Rapid Entire Body Assessment) constitui-se em um método utilizado para avaliar posturas forçadas que se dão com muita frequência em tarefas em que se manipulam pessoas ou qualquer carga animada. Apresenta grande similaridade com o método RULA (Rapid Upper Limb Assessment) e está fundamentalmente direcionado para análises dos membros superiores e para atividades em que são realizados movimentos repetitivos (HIGNETT; McATAMMEY, 2000).

0 objetivo de aplicar este método conjuntamente com os dois de carregamento de cargas manuais é verificar a efetividade dele para a análise da atividade de carregamento de pacientes em relação aos resultados relacionados com as possíveis consequências que as posturas e os pesos carregados podem provocar à saúde das pessoas.

Constitui-se em um novo sistema de análises que inclui fatores de carga posturais dinâmicos e estáticos, a interação pessoa-carga e um novo conceito incorporado chamado "a gravidade assistida" para a manutenção da postura dos membros superiores, ou seja, a ajuda que pode supor a própria gravidade para manter a postura do braço. Por exemplo: é mais custoso manter o braço levantado que tê-lo para baixo, já que a postura mantém-se forçada (ESPANHA, 2010b).

0 método REBA foi inicialmente concebido para estudar posturas forçadas em atividades como a dos fisioterapeutas, que se dedicam a cuidar de pessoas, como também é o caso dos auxiliares de enfermagem, objeto de estudo do presente artigo. Constatou-se também que, no momento de realização do presente estudo, não

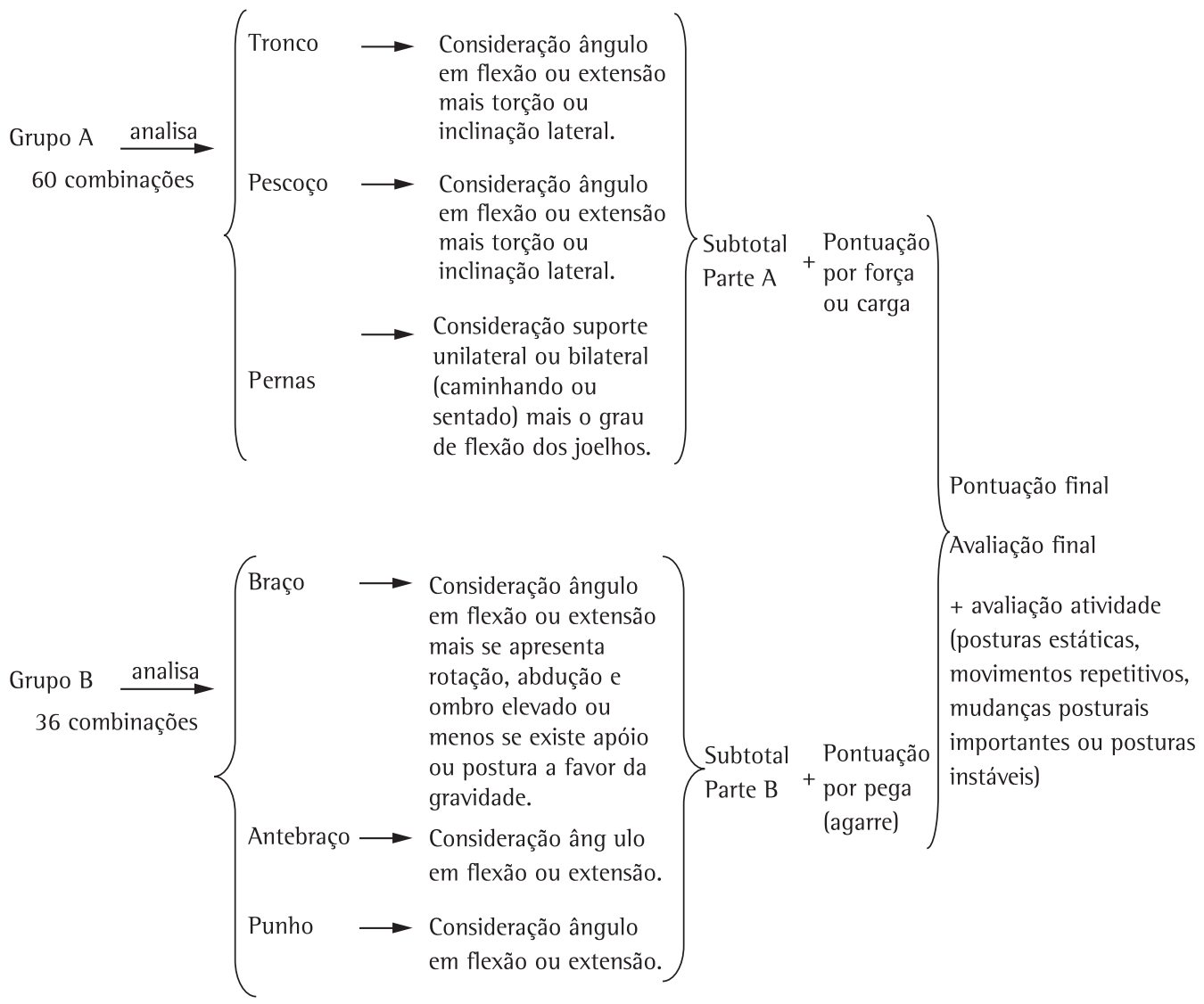

Figura 2. Regiões do corpo para avaliação segundo o método REBA. 
Tabela 1. Níveis de risco e ação.

\begin{tabular}{cccc}
\hline $\begin{array}{c}\text { Nível de } \\
\text { ação }\end{array}$ & Pontuação & $\begin{array}{c}\text { Nivel de } \\
\text { risco }\end{array}$ & $\begin{array}{c}\text { Intervenção e posterior } \\
\text { análise }\end{array}$ \\
\hline 0 & 1 & Inapreciável & Não necessário \\
1 & $2-3$ & Baixo & Pode ser necessário \\
2 & $4-7$ & Médio & Necessário \\
3 & $8-10$ & Alto & Prontamente necessário \\
4 & $11-15$ & Muito alto & Atuação imediata \\
\hline
\end{tabular}

existiam antecedentes no Brasil da aplicação do método REBA para a atividade de carregamento de pacientes.

Para a avaliação das posturas, o método REBA divide as regiões do corpo em dois grandes grupos (Figura 2).

0 resultado da pontuação final possibilita conhecer o nível de risco e a intervenção ou posterior análise da postura avaliada (Tabela 1).

\section{Resultados}

Com relação às características de sintomatologia da população analisada, observou-se que os sintomas apresentados em maior frequência pelos auxiliares de enfermagem estavam relacionados com a fadiga, e $74,3 \%$ da amostra manifestaram que a situação era praticamente constante e que ocorria durante e ao terminar o expediente; $62,9 \%$ sentiam queimação e igual porcentagem formigamento; 54,3\% crepitação; e 91,4\% dores em diferentes partes do corpo, como demonstra a Figura 3.

Cabe ressaltar que 100\% da amostra analisada manifestou a necessidade de realizar grandes esforços físicos para a realização da atividade de manipulação de pacientes e que essa atividade os leva à adoção de posturas com flexão da coluna vertebral e braços desconfortáveis.

Conforme Figura 4, dos 91,5\% auxiliares de enfermagem que apresentaram dores em alguma região do corpo, observa-se que $88,5 \%$ manifestaram ter uma prevalência de dor na região lombar e igual porcentagem na região dorsal. Segundo os próprios trabalhadores, tais dores relacionam-se fundamentalmente com o peso dos pacientes e as posturas adotadas ao pegá-los e durante toda a manipulação, visto que ocorre flexão da coluna devido às condições em que realizam a atividade e a não existência de equipamentos mecânicos apropriados para o carregamento.

Ressalta-se que, durante a pega dos pacientes e o carregamento, é realizado um significativo trabalho muscular estático que, segundo Kroemer e Grandjean (2005), quando comparado com o trabalho dinâmico leva a um consumo maior de energia, a frequências cardíacas maiores e a períodos

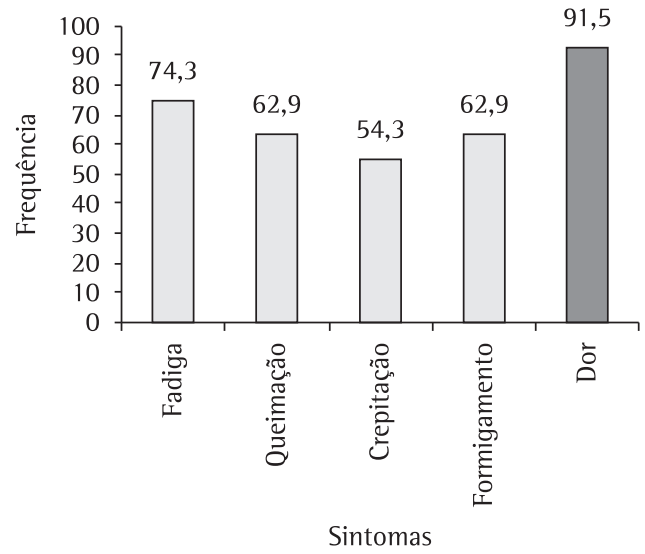

Figura 3. Característica de sintomatologia da amostra analisada.

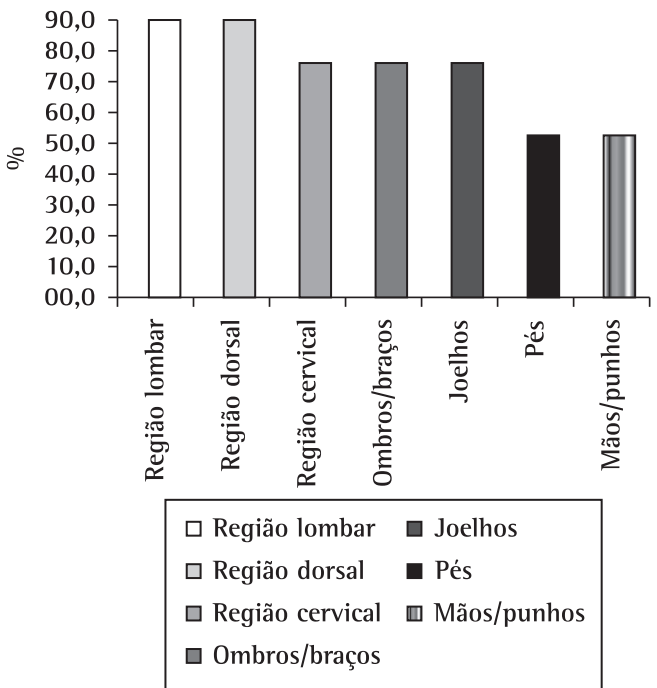

Figura 4. Regiões do corpo mais afetadas em auxiliares de enfermagem.

de restabelecimentos mais longos, existindo queixas em determinadas partes do corpo relacionadas com o trabalho muscular estático. 0 autor destaca que quando existe uma postura do tronco inclinado existem queixas na região lombar com desgastes nos discos intervertebrais. Um músculo sem irrigação sanguínea fatiga-se rapidamente, não sendo possível mantê-lo contraído por mais de 1 ou 2 minutos. A dor que se segue provoca uma interrupção obrigatória do trabalho (IIDA, 2005). Os resultados apresentados neste artigo demonstram que efetivamente a região mais afetada é a lombar (28 de 32 que manifestaram dores).

Através da Figura 5, pode-se observar que a postura do tronco dos auxiliares é totalmente inclinada para a frente tanto no momento da pega como no início do carregamento. Essa postura curvada com flexão do tronco para a frente faz com que aumente 


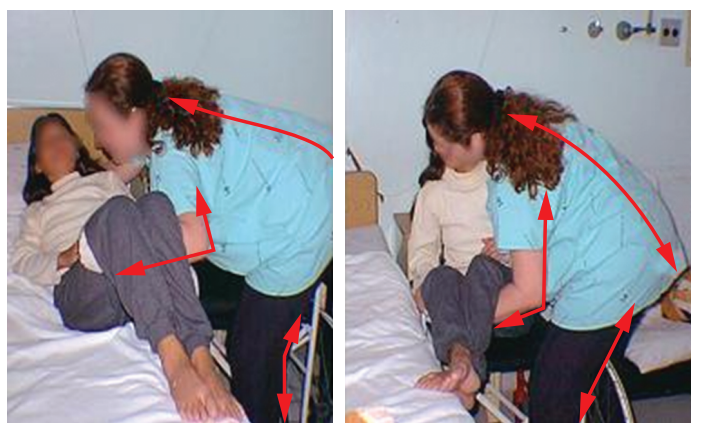

Figura 5. Transferência do paciente do leito para a cadeira de rodas.

consideravelmente a pressão intradiscal, sendo, portanto, exigido ao auxiliar de enfermagem um grande esforço muscular de sustentação contra a ação da gravidade. Como essas posturas são adotadas diariamente e em alta frequência, a probabilidade de ocorrência de dores lombares aumenta. É importante ressaltar que a gravidade dos efeitos adversos ao organismo humano depende fundamentalmente da magnitude do risco, de frequência e do tempo de exposição. Quando os giros para pegar e carregar cargas (no caso estudado pegar e carregar pacientes) são maiores de $30^{\circ}$, chega-se ao limite máximo, a partir do qual se produz um processo de tensão dos músculos do pescoço para ajudar a manter a posição, conforme citado pelo método espanhol.

Do total de auxiliares de enfermagem que participaram do estudo, 74,3\% ainda apresentaram dores na região cervical e igual porcentagem nos ombros/braços e nos joelhos; já 51,4\% apresentaram dores nas mãos/punhos e nos pés. Segundo os próprios trabalhadores, as dores nas mãos correspondem, entre outros fatores, às dificuldades de carregar os pacientes e ao peso destes.

Cerca de 40\% dos entrevistados apresentaram dores em todas as regiões do corpo antes mencionadas e outros $40 \%$ apresentaram dores em mais de 50\% das regiões do corpo. Esta incidência é alta, levando em consideração que o tempo médio de trabalho destes profissionais é de 3,14 anos. É interessante destacar ainda que as dores se manifestavam durante a atividade e no final do expediente, e o mais alarmante é que $37,14 \%$ dos auxiliares de enfermagem pesquisados já começam a jornada de trabalho com dores.

\subsection{Descrição da atividade de transferência do leito hospitalar até a cadeira de rodas}

Os cuidados com a transferência de pacientes, especialmente em unidades de internação, requerem atenção aos princípios da mecânica corporal, prevenindo lesões e riscos ao profissional, como os da amostra analisada, e ao paciente. 0 carregamento de pacientes nas unidades analisadas é realizado de forma manual, ou seja, sem o auxílio de equipamentos mecânicos.

Para deslocar o paciente do leito e colocá-lo na cadeira de rodas devem ser realizadas as seguintes operações:

- Mover o paciente para a beira do leito. Quando o estado geral do paciente permite, solicita-se sua ajuda para facilitar a atividade. Esta atividade geralmente é realizada com o paciente longe do corpo do profissional, o que aumenta o risco;

- Colocar-se de pé ao lado do leito, de frente para o paciente;

- Auxiliar o paciente a mover suas pernas para fora do leito;

- Ficar de frente para a cabeceira do leito, com os pés bem afastados $(45 \mathrm{~cm})$. Novamente observa-se que a posição continua sendo de risco para a atividade, já que quanto mais longe ficar a carga do trabalhador, maior será o peso a ser carregado;

- Pedir para o paciente apoiar-se com as mãos em seus ombros, enquanto o profissional o segura pela cintura trazendo-o aos poucos para a borda do leito;

- Solicitar ao paciente que desça do leito, escorregando suavemente até que os pés fiquem apoiados no chão;

- Estas duas últimas atividades são realizadas quando o paciente pode ajudar; do contrário implicaria maior esforço por parte dos profissionais;

- Girar o corpo do paciente de frente (neste momento os pés do profissional devem estar muito bem posicionados);

- Os joelhos do profissional devem cair em semiflexão, para dar suporte aos joelhos do paciente, até que este esteja sentado e seguro.

Como a altura do leito é maior que a altura máxima do assento da cadeira de rodas, já que o auxiliar de enfermagem transporta o paciente de uma altura maior para uma altura menor, as costas ficam mais curvadas e as pernas mais flexionadas para conseguir realizar a atividade. Quando analisada a atividade de retirada do paciente da cadeira de rodas para ser colocado no leito, observam-se os mesmos problemas relacionados ao peso a ser carregado e às posturas a serem adotadas.

A posição adotada para carregar o paciente é totalmente desconfortável, ficando todo o tempo em pé e com estes totalmente separados, flexão do tronco e giro grande da cintura para poder colocar o paciente no leito, estando a carga bastante separada do corpo. E ao contrário da postura analisada, durante o carregamento do paciente da cadeira de rodas ao 
leito do hospital, o paciente é carregado de uma posição mais baixa para uma mais alta. Isto devido, entre outros fatores, a uma inadequada relação de alturas entre a superfície do leito hospitalar e o assento da cadeira de rodas. Marziale e Carvalho (1998) destacam que a inadequação da altura das superfícies induz o trabalhador a curvar a coluna vertebral ao executar suas atividades podendo ser considerado como fator predisponente ao aparecimento de lombalgias, problema de saúde muito frequente entre os trabalhadores de enfermagem.

\subsection{Aplicação do método NIOSH para avaliação da manipulação manual de cargas}

Analisando a atividade de trabalho dos auxiliares de enfermagem descrita acima, de transferência de pacientes desde o leito hospitalar até a cadeira de rodas, foi aplicado o método NIOSH. A partir da análise pode-se constatar que a distância horizontal da carga ao trabalhador variou entre 30 e $50 \mathrm{~cm}$, sendo que o valor do fator corretivo encontra-se entre 0,83 e 0,50 , respectivamente, sendo assim:

$C L R=23 \times f H \times f V \times f D \times f F \times f A \times f l$

Considerando ainda que a distância horizontal da carga ao trabalhador é de $30 \mathrm{~cm}$, tem-se:

$C L R=23 \times 0,83 \times 0,99 \times 1,0 \times 1,0 \times 0,81 \times 0,9$

$C L R=13,8 \mathrm{~kg}$

$l L=\frac{\text { Peso real da carga }}{C L R}$

E que o peso do paciente é de $25 \mathrm{~kg}$, menor que os existentes nas áreas de internação feminina dos hospitais analisados, tem-se que:

$$
l L=\frac{25 \mathrm{~kg}}{13,8}
$$

$l L=1,81$

Para este caso específico, o Índice de Levantamento (IL) é de 1,81, que significa que aumenta o risco de lesão. Se o peso fosse de $28 \mathrm{~kg}$, o ll passaria para 2,02, o que significaria um grande risco de lesões da coluna e do sistema musculoligamentar.

Caso a distância horizontal da carga ao trabalhador fosse de $50 \mathrm{~cm}$, tem-se:

$C L R=23 * 0,50 * 0,99 * 1,0 * 1,0 * 0,81 * 0,9$

$C L R=8,3 \mathrm{~kg}$ $l L=\frac{\text { Peso real da carga }}{C L R}$

Considerando que o peso do paciente é de $25 \mathrm{~kg}$, menor que os existentes nas áreas de internação feminina dos hospitais analisados, tem-se que:

$l L=\frac{25 \mathrm{~kg}}{8,3}$

$l L=3,01$

Para este caso específico, o Índice de Levantamento (IL) é de 3,01 que significa que aumenta bastante o risco de lesões da coluna e do sistema musculoligamentar.

\subsubsection{Aplicação do método espanhol: “Guia} técnico para avaliação e prevenção dos riscos relativos à manipulação manual de cargas”

Ao aplicar o método espanhol para a mesma situação apresentada pelo método NIOSH, ou seja, durante o carregamento e traslado do paciente desde o leito do hospital até a cadeira de rodas, pode-se constatar que:

- A zona de manipulação do paciente encontra-se um pouco abaixo da altura dos cotovelos até o nível da articulação dos dedos. Os valores de peso teórico recomendado segundo a zona de manipulação devem estar entre 20 e $12 \mathrm{~kg}$ dependendo se a carga é manipulada perto ou longe do corpo, respectivamente. Como analisado anteriormente, durante todo o processo a carga é movimentada longe e carregada perto do corpo. Segundo o método, deve ser escolhida a situação pior, então o peso recomendável é de $12 \mathrm{~kg}$;

- 0 deslocamento vertical não ultrapassa os $25 \mathrm{~cm}$, portanto considera-se que o fator de correção para este conceito é de 1 ;

- 0 giro do tronco alcança valores de até $60^{\circ}$, cujo fator de correção é de 0,8 ;

- 0 tipo de pega é considerado ruim, devido à dificuldade de segurar o paciente, portanto o fator de correção é de 0,90;

- A frequência é baixa e o trabalhador executa a atividade entre uma ou duas horas por dia, sendo assim o fator de correção para a frequência é de 0,95.

A partir destas informações, o peso aceitável para estas condições seria de:

Peso Aceitável $=$ Peso teórico $\times$ Fator correção espaçamento vertical $x$ Fator correção giro $x$ Fator correção agarre $x$ Fator correção frequência Peso Aceitável $=12 \times 1 \times 0,80 \times 0,90 \times 0,95$

Peso Aceitável $=8,21 \mathrm{~kg}$ 
Conforme o resultado, observa-se que nas condições atuais os profissionais só poderiam carregar pesos de aproximadamente 8,21 kg. Quando comparado esse valor com a situação real, observa-se que a probabilidade de que os pacientes possam ser carregados sem que existam riscos dorsolombares para os auxiliares de enfermagem, é muito menor que o máximo recomendado pelo método quando a carga é manipulada à altura dos cotovelos, perto do corpo que é de $25 \mathrm{~kg}$.

Quando se trata de pacientes com um peso maior de $25 \mathrm{~kg}$, como são geralmente os enfermos adultos, essa carga constituiria, por si só, segundo o método, um risco dorsolombar, mesmo estando sendo carregada em condições ergonômicas favoráveis, por isso a necessidade do auxílio de equipamentos mecânicos ou de mais profissionais para distribuir a carga total. Com as mesmas condições atuais de trabalho, estes profissionais poderiam estar realizando essas atividades em salas de internação de crianças, sempre que estas não ultrapassem o valor de $8,2 \mathrm{~kg}$, conforme resultados da aplicação do método para o carregamento de paciente desde o leito do hospital até a cadeira de rodas.

É interessante conhecer qual seria o peso máximo a ser carregado quando modificadas algumas das condições atuais. Para isso o método permite, a partir de medidas corretivas, analisar a possibilidade de aumentar o peso a ser carregado, baseando-se na melhora daqueles parâmetros que apresentam influência negativa. A seguir são descritas algumas alternativas de medidas corretivas para melhoria da situação apresentada, ilustradas através da Figura 6 abaixo:
- Manipular a carga o mais próximo do tronco com a coluna reta, diminuindo a possibilidade de compressão dos discos intervertebrais e evitando ao máximo os giros e inclinações do corpo, assim como realizar levantamentos espaçados. Com estas medidas o peso aceitável a ser carregado resultaria em 15,4 kg;

- Garantir que os leitos fossem reguláveis com relação à altura, de tal forma que o auxiliar de enfermagem conseguisse pegar o paciente à altura do cotovelo, evitando maiores flexões do tronco. Com a aplicação desta medida, o peso aceitável a ser carregado resultaria em 19,2 kg.

Esse valor continua estando muito abaixo dos pesos dos pacientes que são carregados nas áreas de análise, mas sem dúvida a aplicação do método demonstra ser válida para o caso exposto, sendo que, se fossem tomadas medidas adequadas ao trabalho dos auxiliares, estes poderiam carregar com maior frequência pesos maiores sem que representassem riscos dorsolombares.

$\mathrm{Na}$ Figura 6, observa-se um aumento de $11 \mathrm{~kg}$ do peso que pode ser carregado pelo auxiliar de enfermagem, considerando as medidas de melhorias propostas, tais como eliminar as torções e flexões acentuadas do tronco, tão prejudiciais para a saúde.

\subsection{Resultados da aplicação do método REBA}

0 método REBA foi aplicado a 62 posturas analisadas durante o carregamento e traslado do paciente desde o leito do hospital até a cadeira de rodas e a 67 posturas adotadas pelos auxiliares de

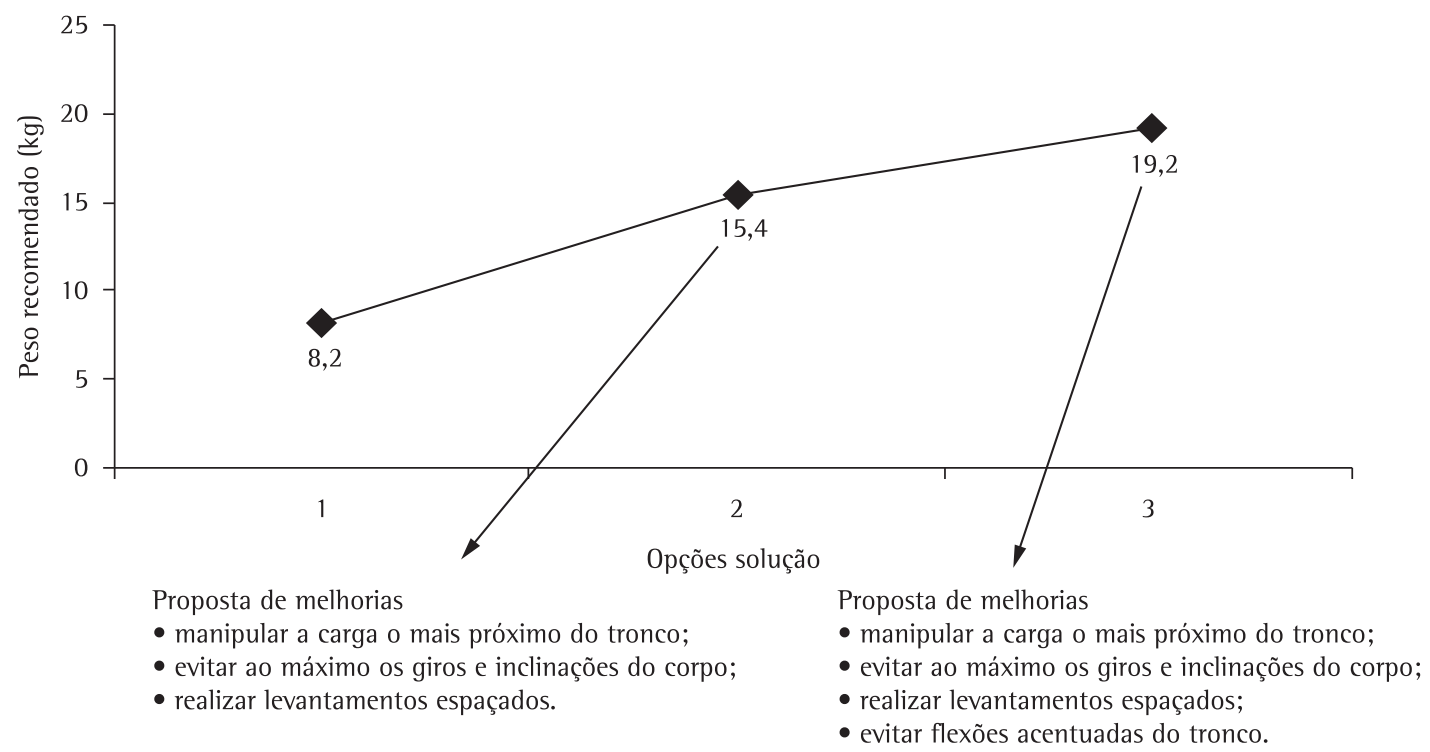

Figura 6. Apresentação gráfica das medidas aplicadas no presente estudo. 
enfermagem durante o traslado dos pacientes na situação inversa, desde a cadeira de rodas até o leito do hospital. Portanto, no total, foram analisadas 129 posturas com o auxílio do método REBA.

Para um melhor entendimento da aplicação do método REBA, foi analisada a mesma postura dos métodos de carregamento de cargas aplicados neste estudo, durante o traslado do paciente desde o leito do hospital até a cadeira de rodas.

Para a situação analisada, destacam-se as seguintes constatações de problemas posturais: o tronco está flexionado formando um ângulo entre $60^{\circ}$ e $80^{\circ} \mathrm{com}$ torções ou giros do tronco que alcançam até $60^{\circ}$. 0 pescoço está flexionado com ângulo maior de $20^{\circ}$, igualmente com torções. As pernas, devido à altura do leito, se encontram em suporte bilateral com postura instável e os joelhos flexionados normalmente mais de $60^{\circ}$. 0 peso a ser carregado pelos auxiliares de enfermagem normalmente ultrapassa $10 \mathrm{~kg}$. Com relação aos membros superiores (considerando só o braço, antebraço e punho do membro direito) pode-se constatar que o braço que está flexionado forma um ângulo entre $20^{\circ}$ e $90^{\circ}$, e que durante a pega e o carregamento do paciente, o ombro permanece elevado. 0 antebraço está igualmente flexionado formando ângulos menores de $60^{\circ}$ e o punho também está flexionado entre $0^{\circ}$ e $15^{\circ}$. A pega é considerada ruim, devido às dificuldades para segurar o paciente, podendo ser considerada como uma pega possível, mas não aceitável. É importante ressaltar que existem mudanças posturais importantes durante a realização da atividade. A Tabela 2 abaixo apresenta os resultados de aplicação do método REBA.
Através dos resultados obtidos através do método REBA, para as 62 posturas analisadas no carregamento de pacientes desde o leito do hospital até a cadeira de rodas, observa-se que 11 posturas $(17,8 \%)$ se encontram em nível de ação 2, existindo um nível de risco médio, sendo necessária uma intervenção ergonômica, 18 posturas $(29,0 \%)$ se encontram em nível de ação 3, existindo um nível de risco alto, sendo necessária uma pronta intervenção ergonômica e 33 posturas $(53,2 \%)$ se encontram em nível de ação 4, existindo um nível de risco muito alto, sendo necessária uma atuação ergonômica imediata.

Ao analisar a situação oposta, ou seja, as 67 posturas durante o carregamento de pacientes desde a cadeira de rodas até o leito do hospital, observou-se que 9 posturas $(13,5 \%)$ se encontram em nível de ação 2, existindo um nível de risco médio, sendo necessária uma intervenção ergonômica; já 22 posturas $(32,8 \%)$ se encontram em nível de ação 3 , existindo um nível de risco alto, sendo necessária uma pronta intervenção ergonômica; e 36 (53,7\%) posturas se encontram em nível de ação 4, existindo um nível de risco muito alto, sendo necessária uma atuação ergonômica imediata.

A análise das 129 posturas, conforme pode ser observado pela Figura 7 demonstra que 109 (84,5\%) delas se encontram em um nível de risco alto e muito alto, precisando de uma intervenção ergonômica urgente e as restantes posturas (20) que representam 15,5\% do total, precisam de intervenção, mas não tão imediata. Não existem diferenças significativas quando comparado o membro superior direito com o esquerdo, analisados separadamente conforme estabelecido pelo método.

Tabela 2. Resultados da aplicação do método REBA.

\begin{tabular}{|c|c|c|c|c|}
\hline Item & Avaliação da postura & Flexão & Torção ou giros & Pontuação total \\
\hline 1 & Tronco & Entre $60^{\circ}$ e $80^{\circ}=4$ & Até $60^{\circ}=1$ & $4+1=5$ \\
\hline 2 & Pescoço & Maior de $20^{\circ}=2$ & Torção $=1$ & $2+1=3$ \\
\hline 3 & Pernas & Bilateral, postura instável = 2 & Joelhos mais de $60^{\circ}=2$ & $2+2=4$ \\
\hline 4 & \multicolumn{3}{|c|}{ Pontuação do grupo “A” (postura do pescoço, tronco e pernas) } & 9 \\
\hline 5 & \multicolumn{2}{|c|}{ Avaliação da força ou carga exercida } & Peso ultrapassa $10 \mathrm{~kg}$ & 2 \\
\hline 6 & \multicolumn{3}{|c|}{ Total do grupo “A” (soma dos itens 4 e 5) } & $9+2=11$ \\
\hline 7 & Braços & Entre $20^{\circ} \mathrm{e} 90^{\circ}=3$ & Ombro permanece elevado $=1$ & $3+1=4$ \\
\hline 8 & Antebraços & Menores de $60^{\circ}$ e maiores de $100^{\circ}=2$ & ---- & 2 \\
\hline 9 & Punhos & Entre $0^{\circ}$ e $15^{\circ}=1$ & ---- & 1 \\
\hline 10 & \multicolumn{3}{|c|}{ Pontuação do grupo “B” (postura do braço, antebraço e punho) } & 5 \\
\hline 11 & Pega ou agarre & \multicolumn{2}{|c|}{ Possível, mas não aceitável } & 2 \\
\hline 12 & \multicolumn{3}{|c|}{ Total do grupo "B" (soma dos itens 10 e 11) } & 7 \\
\hline 13 & \multicolumn{3}{|c|}{ Pontuação da atividade: Total grupo “A” (item 6) e grupo “B” (item 12) } & 12 \\
\hline 14 & Avaliação da atividade & \multicolumn{2}{|c|}{ Mudanças posturais importantes, deve-se acrescentar 1} & 1 \\
\hline 15 & \multicolumn{3}{|c|}{ Pontuação final da atividade } & $12+1=13$ \\
\hline 16 & \multicolumn{3}{|c|}{$\begin{array}{l}\text { Níveis de risco ou ação muito alto }=4 \\
\text { Intervenção e posterior análise }\end{array}$} & Atuação imediata \\
\hline
\end{tabular}


Carregamento paciente desde o leito do hospital até a cadeira de rodas ( 62 posturas)

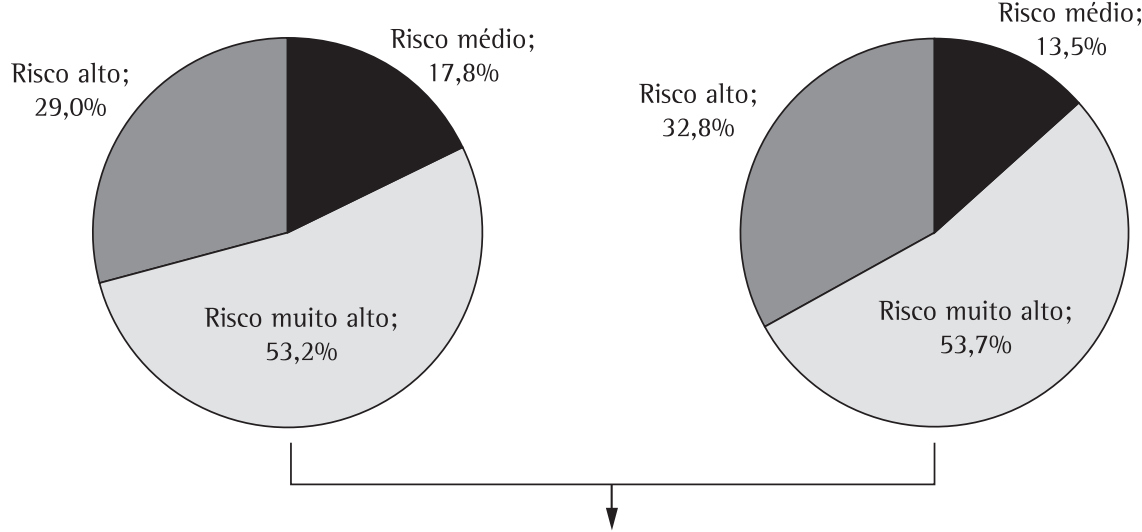

Análise total das posturas durante o carregamento de pacientes desde o leito do hospital até a cadeira de rodas e vice-versa (129 posturas)

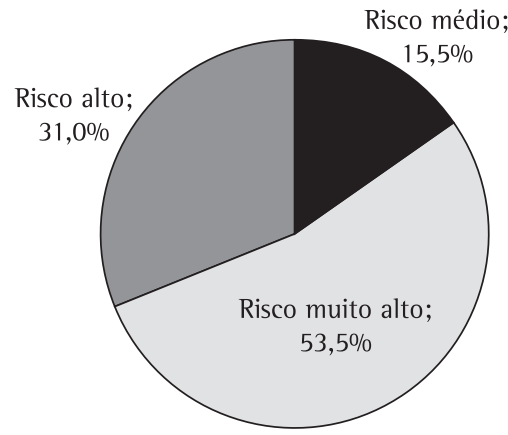

Carregamento paciente desde a cadeira de rodas até o leito do hospital (67 posturas)

Risco médio;

Figura 7. Resultados obtidos através da aplicação do método REBA.

Conforme resultados apresentados acima, pode-se constatar a necessidade de atuação ergonômica imediata, assim como confirma os resultados dos métodos aplicados anteriormente, que demonstram o risco a que os auxiliares de enfermagem estão sujeitos ao realizar tais atividades nas atuais condições.

\section{Considerações finais}

A análise de posturas e carregamento de cargas manuais no trabalho na área da saúde constitui aspecto de vital importância na garantia da saúde dos trabalhadores em relação às possíveis doenças musculoesqueléticas. Através deste estudo, pode-se concluir que os profissionais de enfermagem que trabalham com carregamento de pacientes, especificamente durante as atividades de manipulação deste do leito do hospital até a cadeira de rodas e vice-versa, estão expostos a fatores de riscos motivados pela atividade e que, no caso da amostra analisada, confirma-se a relação das atividades realizadas com 
de rodas ao leito hospitalar e vice-versa, assim como em outras atividades nas quais o sacrifício e o esforço humano são uma constante, tornando-se necessárias algumas considerações importantes inerentes à prevenção de transtorno postural, bem como manutenção e/ou melhorias do bem estar geral no ambiente de trabalho. Entre elas destacam-se:

- Utilizar ajudas mecânicas adaptadas à situação analisada a fim de minimizar o esforço realizado pelos auxiliares de enfermagem durante a manipulação de pacientes;

- Utilizar equipamentos mecânicos como cadeiras de rodas que permitam a realização com maior facilidade das atividades;

- Incentivar o pessoal à participação de mais de um profissional, quando o peso do paciente for elevado, repartindo a carga total a ser carregada para diminuir os efeitos danosos ao organismo humano;

- Inserir a capacitação continuada para que os auxiliares de enfermagem evitem assumir atitudes posturais inadequadas que levem a problemas de saúde, sendo recomendado:

- Pegar e carregar a carga o mais próximo possível do tronco com a coluna reta;

- Eliminar ou evitar ao máximo os giros e inclinações;

- Possibilitar espaço suficiente para a realização da atividade, entre outras.

Considerando que a atividade de manipulação e carregamento de pacientes constitui por si só um fator de risco dorsolombar para os auxiliares de enfermagem, que pode ser comprovado através das associações entre os três métodos aplicados, assim como os problemas ergonômicos destacados neste estudo de caso, espera-se que esta pesquisa possa servir de subsídio para o trabalho preventivo junto aos auxiliares de enfermagem em prol de melhores condições de trabalho e, consequentemente, melhor qualidade de vida e saúde destes profissionais.

\section{Referências}

BATIZ, E. C. Métodos de análises de posturas e carregamento de cargas manuais. Universidade Federal de Santa Catarina, 2001. Apostila.

BRASIL. Ministério de Trabalho e Emprego - MTE. Portaria GM $\mathrm{n}^{\circ}$ 3.214, de 08 de junho de 1978. NR-17. Ergonomia. Diário Oficial da República Federativa do Brasil, Brasília, DF, 06 jul. 1978. Disponível em: <http://portal.mte.gov. br/data/files/FF8080812BE52160012BE524821A13D0/ nr_17.pdf>. Acesso em: 01 mar. 2011.
BRASIL. Ministério de Trabalho e Emprego - MTE. Portaria ministerial no 397, de 9 de outubro de 2002. Classificação Brasileira de Ocupações. Diário Oficial da República Federativa do Brasil, Brasília, DF, 2002. Disponível em: <http://www.mtecbo.gov.br/cbosite/pages/pesquisas/ BuscaPorTituloResultado.jsf>. Acesso em: 15 jan. 2010.

BRASIL. Presidência da República. Casa Civil. Subchefia para Assuntos Jurídicos. Decreto-Lei $n^{\circ}$ 5.452, de 01 de maio de 1943. Consolidação das Leis Trabalhistas. Diário Oficial da República Federativa do Brasil, Brasília, DF, 09 ago. 1943. Disponível em: <https://www.planalto.gov. br/ccivil_03/decreto-lei/Del5452compilado.htm>. Acesso em: 01 mar. 2011.

BRASIL. Senado Federal. Parecer $n^{\circ}$ 1.337, de 2005. Diário Oficial da República Federativa do Brasil, Brasília, DF, 2005. Disponível em: <http://www.senado.gov.br/ atividade/Materia/getPDF.asp?t=35920>. Acesso em: 01 mar. 2011.

CENTRO PANAMERICANO DE INGENIERÍA SANITARIA Y CIENCIAS DEL AMBIENTE - CEPIS. La prevención de las lesiones de espalda en el trabajo hospitalario. 2002. Disponivel em: <http://www.bvsde.ops-oms.org/eswww/ fulltext/repind61/st/st.html>. Acesso em: 09 ago. 2010.

ESPANHA. Ministerio de Trabajo e Inmigración. Instituto Nacional de Seguridad e Higiene en el Trabajo. Guía técnica para la evaluación y prevención de los riesgos relativos a la manipulación manual de cargas. Disponível em: <http://www.insht.es/InshtWeb/Contenidos/Normativa/ GuiasTecnicas/Ficheros/cargas.pdf>. Acesso em: 15 set. 2010a.

ESPANHA. Ministerio de Trabajo e Inmigración. Instituto Nacional de Seguridad e Higiene en el Trabajo. NTP 601 - Evaluación de las condiciones de trabajo: carga postural. Método REBA (Rapid Entire Body Assessment). Disponível em: <http://www.insht.es/ InshtWeb/Contenidos/Documentacion/FichasTecnicas/ NTP/Ficheros/601a700/ntp_601.pdf>. Acesso em: 29 nov. 2010b.

GÓMEZ-MORAN, M. C.; VIVAS, J. S. Análisis de la carga postural entre auxiliares de enfermería de Residencias de ancianos. In: CONGRESO NACIONAL DE SEGURIDAD Y SALUD EN EL TRABAJO, 12., 2001, Valencia, España. Anais... Valencia, 2001. Disponivel em: <http://www. mtas.es/lnsht/Xllcongreso/Posters/PSutilJ2.pdf>. Acesso em: 21 nov. 2007.

HIGNETT, S.; McATAMMEY, L. Rapid Entire Body Assessment: REBA. Applied Ergonomics, v. 31, p. 201-5, 2000. http:// dx.doi.org/10.1016/S0003-6870(99)00039-3

IIDA, 1. Ergonomia: Projeto e Produção. 2. ed. São Paulo: Blucher 2005. 614 p.

KROEMER, K. H. E.; GRANDJEAN, E. Manual de ergonomia: adaptando o trabalho ao homem. 5. ed. Porto Alegre: Bookman, 2005.

MAGAZINE. Aligera la Carga. Revista de la Agencia Europea para la Seguridad y la Salud en el Trabajo, 2007. Disponível em: <http://osha.europa.eu/es/publications/ magazine/10>. Acceso em: 07 jun. 2010. 
MARZIALE, M. H. P.; CARVALHO, E. C. Condições ergonômicas do trabalho da equipe de enfermagem em unidade de internação de cardiologia. Revista Latino-americana de Enfermagem, v. 6, n. 1, p. 99-117, 1998. PMid:9592557. http://dx.doi.org/10.1590/S0104-11691998000100013

MERCHÁN, M. E. P.; JURADO, A. E. Nuevas condiciones laborales para el profesional de enfermería. Organización Panamericana de La Salud, Centro Panamericano de Ingeniería Sanitaria y Ciencias del Ambiente - CEPIS, 2002. Disponível em: <http://www.cepis.ops-oms.org/bvsacd/ cd49/nuevas.pdf>. Acesso em: 12 out. 2007.

REMESAL, A. F. Evaluación de las condiciones ergonómicas en el sector sanitario. Valencia, 2005. Disponível em: <http://
www.seslap.com/seslap/html/curCong/congresos/ xvcongreso/dia2/mesa4_AlbertoFerrerasRemesal.pdf>. Acesso em: 13 fev. 2010.

SANDERS, M. S.; McCORMICK, E. J. Human factors in engineering and design. 17th ed. McGraw-Hill, Inc., 1993.

VALENZUELA, M. E. F. Enfoque ergonómico para abordar riesgos por manipulación y traslados de pacientes. Revista Seguridad en Acción, n. 72, 2004. Disponível em: <http://www.mutual.cl/capacita/cont/imagenes/ rev0904.pdf>. Acesso em: 13 fev. 2010.

VAN COT, H. P.; KINKADE, R. G. Human Engineering Guide to Equipment Design. Washington: US Government Printing Office, 1972.

\title{
Comparison between lifting loads and postural analysis of nursing auxiliaries
}

\begin{abstract}
Nursing auxiliaries are exposed to harmful workloads due to several factors, such as: the weight to be manipulated, the postures assumed and the physical conditions of hospitals. The aim of this paper was to present the results of the application of three methods - two related to lifting and another to postural analysis - to verify the existence of risks of lumbar back problems in nursing auxiliaries when manipulating and lifting patients. The N1OSH method and the "Technical Guide for Evaluation and Prevention of Relative Risks to Manual Manipulation of Loads" were used to analyze the manipulation of loads, while the Reba method was used for the postural analysis of these professionals. In general, results show symptoms of fatigue and body aches, especially in the lumbar, dorsal and cervical areas. It was demonstrated that the manipulated weight is above the recommended value, characterizing high risk to the lumbar back. Some procedures are proposed in order to improve the analyzed working conditions.
\end{abstract}

\section{Keywords}

Lifting of loads. Nursing auxiliaries. Postural analysis. 